\title{
A taxonomic study of physiological responses to a psychological stress
}

\author{
P. K. BRIDGES, M. T. JONES, AND D. LEAK ${ }^{1}$ \\ From the Department of Psychological Medicine, Royal Free Hospital, London, \\ Sherrington School of Physiology, St. Thomas's Hospital, London, and \\ McMaster University Medical Unit and McGregor Clinic, Hamilton, Ontario, Canada
}

The ascending brain-stem reticular formation appears to be a diffuse projecting system that activates the cerebral and cerebellar cortex (Moruzzi and Magoun, 1949). If this area is stimulated electrically, the cortical electroencephalograph exhibits desynchronization with decrease in amplitudes and increased frequencies. The associated behavioural response has been termed arousal; which is a continuum from relaxed wakefulness, to curiosity and attentiveness, extending to strong emotions such as anxiety and panic, anger and rage. It is usually difficult to define accurately the psychological experience of a subject in response to stress, and the term anxiety is often rather loosely employed in these circumstances. But other emotional states, such as anger or shame, may be involved to a variable extent.

Associated with arousal states there is a widespread increase in physiological activity, including elevation of the level of blood corticotrophin (Hodges, Jones, and Stockham, 1962) and therefore of plasma 17-hydroxycorticosteroids (Bliss, Migeon, Branch, and Samuels, 1956; Mason, 1959), and of urinary catecholamines (Levi, 1965). There is also tachycardia and raised arterial pressure (Schachter, 1957). The relationships between the emotional responses to stress and the associated physiological stimulation are complex and present a number of problems (Martin 1961; Bridges, Jones, and Leak, 1968). For example, although the reactions of individual physiological systems to stress have been the subject of numerous studies, there has been less work concerned with the relationships between different physiological responses, which may offer an assessment of their relevance and reliability as measures of psychological stress. The intercorrelations reported have usually been low, with few

\footnotetext{
${ }^{1}$ Formerly at King's College Hospital, London.
}

significant findings (Lader and Wing, 1966; Bridges et al., 1968). However, there is some evidence thae subjects tend to show individual patterns of respon siveness which may be reproducible over time and consistent over a number of stressful stimuli (Laceyf Bateman, and Vanlehn, 1953).

The present report attempts to study further interrelationships between responses, and also 300 investigate some possible determinants of the types of responsiveness. For this purpose, we studied medical students taking an oral examination which appears to constitute a potentially severe a did reliable anxiety-producing stress of entirely psyctō logical kind. Plasma cortisol concentration, urinafy catecholamine excretion, urine volume, heart rate and blood pressure were measured at the time of the examination and similar control observations were taken some two months later.

The possible relevance of physique and person ality to physiological responsiveness has been dis $\vec{P}$ cussed previously (Bridges and Jones, 1967; 1968? and the present study is a further development of that work. It concerns the relationship of the pattern of responses to physique and personality, which has been studied by means of numerical taxonomy.

\section{INVESTIGATION BY NUMERICAL TAXONOMY}

Classification is the process and result of sorting a population into groups on the basis of relatione ships; and the theoretical study of classification, including its bases, principles, and methods is termeof taxonomy. Numerical taxonomy aims to place the process on a quantitative basis and so introducer objectivity, repeatability, and precision into the classification (Baron and Fraser, 1968).

In general, taxonomic methods are employed too group together entities or individuals with common 
features and some of the numerous measures of resemblance that may be used have been described by Sokal and Sneath (1963). These assessments of multiple relationships between individuals include correlations, distances, and associations by similarities; and the elaborate mathematical procedures involved have been made possible by the use of computers.

CLUSTER ANALYSIS In the present study the aim was to construct a classification of the physiological responses resulting from the stress situation, in relation to individual characteristics. For this purpose a cluster analysis was carried out, employing the classification program (CLASP) written for the Orion Computer at Rothamsted Experimental Station.

No formal rules can be laid down for finding clusters, as the concept of a cluster lacks precise definition. The essential criterion is that any two units belonging to the same cluster should, on average, show a higher coefficient of similarity with each other than with those belonging to other clusters (Sheals, 1964). The method of clustering used in CLASP is to define the similarity coefficient between each pair of objects as a number within the range $0-1$. Objects which are identical in all respects then have a similarity 1 , while those which are entirely dissimilar become 0 . A similarity matrix is produced and forms the basis for the cluster analysis.

Of the various methods of clustering a matrix of coefficients, that of median sorting has been employed here, which is similar to the centroid clustering method of Sokal and Michener (1958). In this procedure, if $i$ and $j$ are two objects with the highest similarity, then $i$ and $j$ constitute the first group which is represented by its node, the mid-point of $\mathrm{j}$ and $\mathrm{j}$ in geometric representation. Similarities between this group and othe: objects and groups are recalculated and the process is repeated. The node of a group changes as objects or groups are added to it, the new node always being the unweighted midpoint of the nodes of component groups.

The representation of the results of clustering is by a dendrogram (see Fig. 1). While this has a familiar tree-like representation, it does not, of course, imply arborizing descent but merely indicates at the junction of the stems the levels of similarity at that junction. Statistical significance is not assigned to the similarity coefficients as the magnitude of the individual coefficient is of less importance than the average level at which groups are formed. As the average value decreases the groups become more heterogeneous.

PRINCIPAL CO-ORDINATE ANALYSIS This is one of the methods of deriving a representation of the multivariate sample in a small number of dimensions, whereby the similarity matrix, which formed the basis of the cluster analysis, is transformed into a distance matrix. The resulting co-ordinates refer to principal axes obtained by evaluating the latent roots and vectors of this matrix (Gower, 1966).

\section{METHODS}

All 48 male students at one medical school taking the second MB anatomy oral examination agreed to take part in the investigation and they were about 20 years old.

The examination lasted about 15 minutes and, before it began, each subject voided urine, which was discarded. Immediately the examination was completed the heart rate was taken over one minute and the blood pressure was recorded by the conventional auscultation method with the student seated and his arm in the horizontal position. Each subject then drank $250 \mathrm{ml}$. of water, to facilitate diuresis, and rested until one hour after the examination had begun, when the bladder was emptied and urine collected into bottles containing sodium metabisulphite and sodium fluoride. These were stored at $-20^{\circ} \mathrm{C}$ for subsequent measurement of adrenaline and noradrenaline by differential fluorimetry as described by Leak, Brunjes, Johns, and Starr (1962), the results being calculated by the method of Brunjes and Wybenga (1963).

There is a delay of some 30 minutes between the stimulus and the resulting increase in plasma cortisol concentration (Hodges, Jones, Elithorn, and Bridges, 1964), therefore blood was taken 30 minutes after the examination began. The five millilitres of venous blood obtained was collected into a tube containing heparin which was centrifuged at once and the plasma stored at $-20^{\circ} \mathrm{C}$ for later estimations of plasma cortisol by a modification of the method of Zenker and Bernstein (1958). This method measures 11-hydroxycorticosteroids and in the modification fluorescence was read 20 minutes after the addition of fluorescent agent, at which time the effect of cortisol is maximal but not that for the much smaller amount of corticosterone present, so that estimation of the latter was minimized.

Some two months later similar collections were carried out at approximately the same time of day as the examination, to provide control data. On this occasion, each subject voided urine, then drank $250 \mathrm{ml}$. of fluid and rested for one hour when urine was collected for determination of catecholamines. During the period of rest, heart rate and blood pressure were recorded, and a blood sample was taken as before. All estimations of heart rate and blood pressure were taken by a single observer.

At the time of the control estimations the Eysenck Personality Inventory, Scale A, (EPI) (Eysenck and Eysenck, 1964) was completed. This personality questionnaire consists of two scores in the dimensions of extraversion-introversion ( $E$ score) and neuroticism or emotional stability ( $\mathrm{N}$ score). In addition, physical measurements were taken to determine the phenotype as described by Parnell (1958), and these included height and 
weight. The phenotype gives an assessment of physique in three components, each on a seven point scale; they consist of fatness (F), muscularity (M), and linearity (L). The phenotypes may be grouped by primary and secondary components so that, for example, the primarily linear group includes those with secondary muscularity (Lm), secondary fat (Lf) and both secondary components equal (L).

\section{RESULTS}

The mean results for the estimates of physique and personality for all 48 subjects are given in Table 1 . The numbers of subjects in the various phenotype groups are given in Table 2.

The means of the physiological variables for all the subjects are presented in Table 3. All the mean results found at the time of the examination are

TABLE 1

MEANS OF PERSONAL DATA ALL SUBJECTS

\begin{tabular}{cr} 
EPI E score & $11.98 \pm 4 \cdot 10$ \\
N score & $9.08 \pm 4.44$ \\
Phenotype F & $3.21 \pm 0.94$ \\
M & $4 \cdot 17 \pm 0.91$ \\
L & $3.54 \pm 1.09$ \\
Height (in.) & $70.78 \pm 2.28$ \\
Weight (lb.) & $158.54 \pm 17.14$ \\
& \\
\hline
\end{tabular}

TABLE 2

PHENOTYPE CLASSIFICATION

\begin{tabular}{lr} 
& no. \\
\hline L, Lm, Lf & 9 \\
M, M1, Mf & 22 \\
F, Fm, F1 & 6 \\
LF & 3 \\
FM & 4 \\
ML & 4 \\
& 48 \\
\hline
\end{tabular}

significantly larger than those obtained under control conditions, except that in the case of urine volume there is a significant reduction.

The measures of body build and of personality, together with the stress values of the physiological variables, were included in the cluster analysis. The full data used in this analysis for each of the 48 subjects was therefore as follows: stress values of systolic and diastolic blood pressure, pulse pressure, heart rate, plasma cortisol concentration, urine $\vec{F}$ volume, total catecholamine excretion per hour, adrenaline excretion rate, noradrenaline excretion rate; together with the $\mathrm{E}$ score, $\mathrm{N}$ score, height, weight, and values of $F, M$, and $L$.

The resulting dendrogram is given in Fig. 1, in $\triangle$ which there is a trend of decreasing similarity from is above downwards. Two main sub-groups appear to $\overrightarrow{0}$ be formed whose levels of similarity are $85 \%$ or above. One contains 18 subjects, from 2 to 33 in the $\vec{\omega}$ dendrogram (group A); and the other nine subjects from 3 to 44 (group B). The phenotypes are given in the figure and it can be seen that group B consists exclusively of primarily muscular subjects, nearly all of whom have secondary linearity. Group $\bar{B}$ contains mostly subjects with primarily linear or f $\vec{f}$ physiques. Of a total 16 subjects with a major lineat component (L, Lm, Lf, LF, ML), 11 appear i⿱ this group.

In Table 4 the mean values of the personal dati are given separately for groups $\mathbf{A}$ and $\mathbf{B}$, and als for the remaining subjects grouped together (R The groups differ significantly in their physiques but not in relation to personality.

The means of the physiological variables are given for the three groups in Table 5 . In this table both the mean control values and also the mean stress values are included, although the groups were obtained by clustering only the stress values. The groups differ in relation to the control heart rates and also in relation to noradrenaline excretion in both control

TABLE 3

MEANS OF PHYSIOLOGICAL VARIABLES

ALL SUBJECTS

\begin{tabular}{|c|c|c|c|}
\hline & Control & Stress & $\begin{array}{c}\text { Significance } \\
\text { of } \\
\text { Differences } \\
P\end{array}$ \\
\hline $\begin{array}{l}\text { Systolic pressure }(\mathrm{mm} \mathrm{Hg}) \\
\text { Diastolic pressure }(\mathrm{mm} \text { Hg) } \\
\text { Pulse pressure }(\mathrm{mm} \mathrm{Hg}) \\
\text { Heart rate }(\text { beats } / \mathrm{min}) \\
\text { Plasma cortisol }(\mu \mathrm{g} / 100 \mathrm{ml} .) \\
\text { Urine volume }(\mathrm{ml}) \\
\text { Total catecholamines }(\mu \mathrm{g} / \mathrm{hr}) \\
\text { Adrenaline }(\mu \mathrm{g} / \mathrm{hr}) \\
\text { Noradrenaline }(\mu \mathrm{g} / \mathrm{hr})\end{array}$ & $\begin{array}{c}122 \pm 12 \\
79 \pm 8 \\
43 \pm 9 \\
72 \pm 11 \\
19.72 \pm 5.40 \\
74.18 \pm 44.41 \\
2.70 \pm 1.96 \\
0.52 \pm 0.32 \\
2.19 \pm 2.01\end{array}$ & $\begin{array}{c}144 \pm 21 \\
92 \pm 11 \\
52 \pm 18 \\
103 \pm 19 \\
32 \cdot 81 \pm 9 \cdot 51 \\
49.75 \pm 33 \cdot 12 \\
4.92 \pm 2.97 \\
1.21 \pm 0.90 \\
3.71 \pm 3.09\end{array}$ & $\begin{array}{l}<\cdot 001 \\
<\cdot 001 \\
<\cdot 001 \\
<\cdot 001 \\
<\cdot 001 \\
<\cdot 01 \\
<\cdot 001 \\
<\cdot 001 \\
<\cdot 01\end{array}$ \\
\hline
\end{tabular}

\pm S.D. 


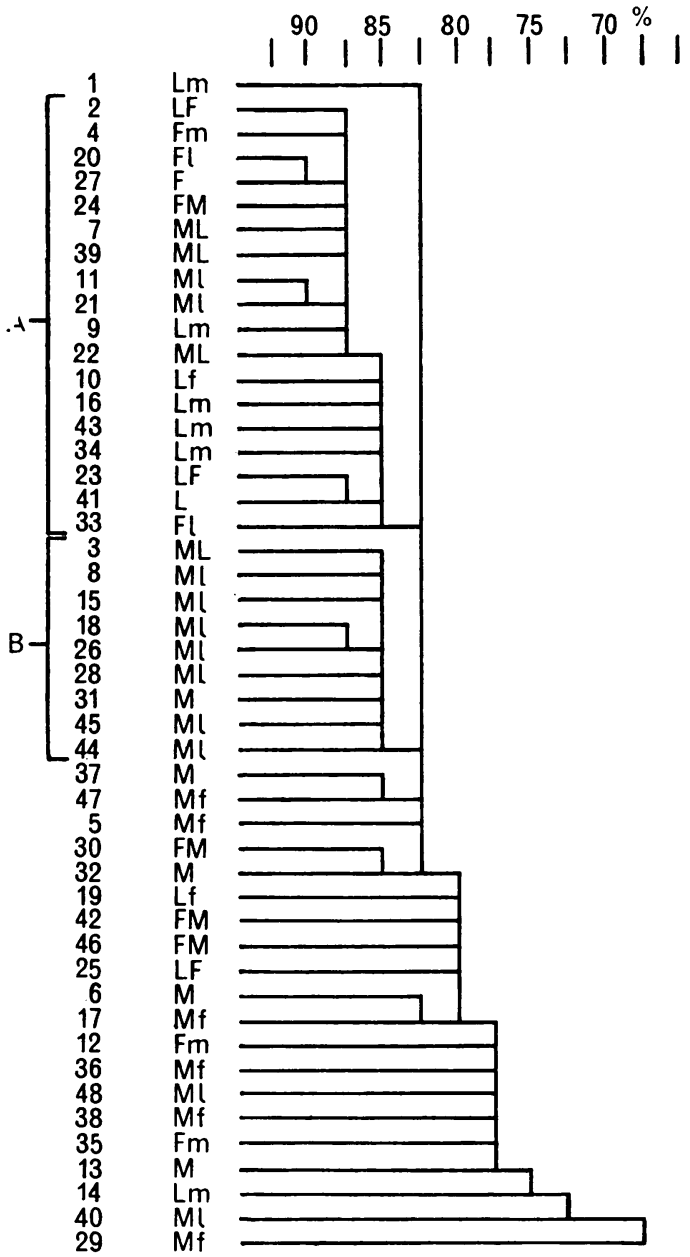

FIG. 1. Dendrogram produced by the cluster analysis, with similarity levels given at the top. For each subject is given his identification number and phenotype classification. Group $A$ is from subject number 2 to 33, and group $B$ from 3 to 44.

and stress conditions, which is reflected in similar differences in total catecholamine excretion.

By plotting the subjects' co-ordinates on pairs of three latent vectors, it was found that the best discrimination was given by vectors 1 and 3 , and these appear to be related to the phenotypes, as shown in Fig. 2. Vector 1 has a negative relationship with the degree of muscularity, while vector 3 is associated negatively with linearity and in a positive direction with fatness.

\section{DISCUSSION}

The mean results for the $\mathrm{E}$ and $\mathrm{N}$ scores correspond closely with those given by Eysenck and Eysenck
(1964) for a group of university students $\left(E_{A}=\right.$ $11.095, N_{A}=10.006$ ). The preponderance of primarily muscular students shown in Table 2 and the relative mean phenotype components in Table 1 confirms a previous finding that medical students tend to be mainly muscular and to have low fat components (Parnell, 1953). The mean heights and weights of large groups of male workers have been reviewed by Khosla and Lowe (1968). The mean weight of the present students is intermediate between the two most recent samples given of the same age group, while the students' mean height is greater than both the samples.

It was, of course, inevitable that such a highly selected group of subjects would show a relatively narrow distribution of personal characteristics. However, the sub-groups produced by the cluster analysis exhibited differences in phenotype components, height, and weight, but showed no significant differences between the results of the personality tests.

During the control period, both groups A and B had a significantly higher noradrenaline output than the remaining subjects. After the stress, group B produced a significantly higher mean excretion rate than the other two groups. Group A showed no mean increase of noradrenaline output in response to the stress, while there was a highly significant increase in both other groups. These differences in noradrenaline excretion between the groups are not, however, reflected in the blood pressure results, and all groups show highly significant increases in both systolic and diastolic pressures.

Thus group B, which had the highest muscularity and lowest fat component, showed the most marked noradrenaline response to stress; while group A, characterized by predominant linearity with the lowest muscular component, produced no noradrenaline response on average. The adrenaline responses were closely similar for all groups. These findings are of interest because of several reports that there is a differential catecholamine response on the basis of the evoking psychological experience. Noradrenaline output has been affirmed to be particularly associated with active, aggressive behaviour, while adrenaline excretion is more related to anxiety and tension (Elmadjian, Hope, and Lamson, 1957; Schildkraut and Kety. 1967). Of course, muscular subjects may tend to respond to certain situations with anger rather than anxiety, although it was not felt possible to assess the precise subjective experiences at the time of the examination.

The linear group $\mathbf{A}$ had the highest mean stress plasma cortisol level, while the mainly muscular group B had the lowest. These differences are not significant but accord with a trend we have pre- 
TABLE 4

MEANS OF PERSONAL DATA BY GROUPS

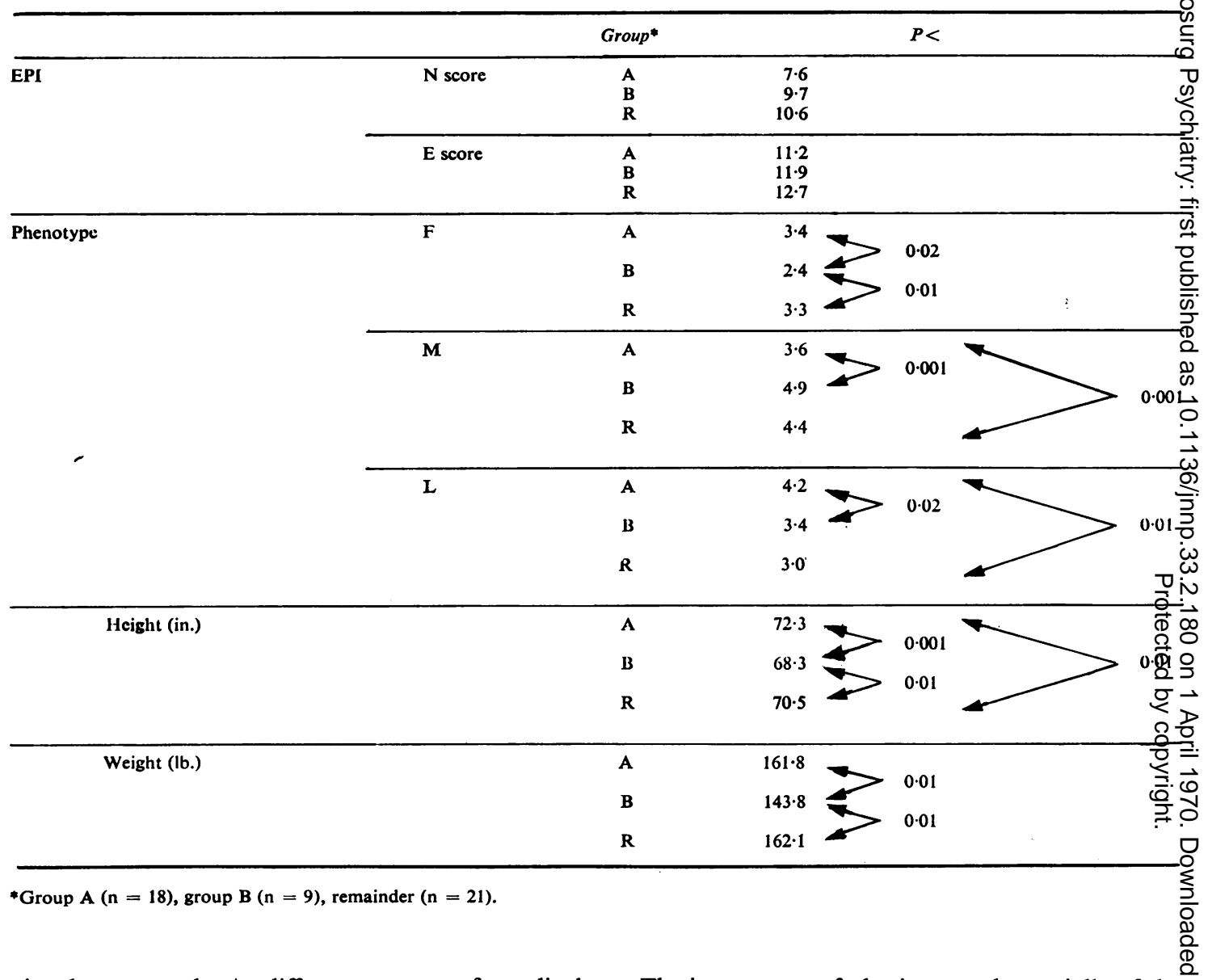

viously reported. A different group of medical students from those included in this investigation were studied one year previously in the same circumstances. When the results for those students were combined with the present values, making a total group of 80 students, a significant negative correlation was found between the muscularity rating and stress plasma cortisol levels $(-0.225)$ (Bridges and Jones, 1968).

Thus, factors related to body build appear to be of importance in determining some physiological responses to stress. High degrees of muscularity are associated with smaller adrenocortical responses than those found among mainly linear subjects, and also with greater noradrenaline release. These differences may be related to varying emotions evoked by the stress but any such possible predispositions have not been revealed by the personality tests used in this study.
The importance of physique, and especially of the $\overrightarrow{\vec{A}}$ muscular component, is also emphasized by the finding that the first latent vector obtained from theprincipal co-ordinate analysis seems to be closelyọ. related to muscularity, while the third vector appears to be associated with the other two phenotype components.

In investigations which depend upon the measure-3 ment of physiological variables as a means of quantifying psychological stress, it is usually assumed that there is a direct relationship between arousal and physiological stimulation. That this is an over-simplification is suggested by the reports of low correlations between physiological parameters, of relative specificity of individual response patternsor and the fundamental association of body build rather than personality measures with some of the responses. Before physiological concomitants of emotional states can be usefully employed in their 
TABLE 5

MEANS OF PHYSIOLOGICAL VARIABLES BY GROUPS

\begin{tabular}{|c|c|c|c|c|c|}
\hline & Group* & Control & $P<$ & Stress & $P<$ \\
\hline Systolic pressure $(\mathrm{mm} \mathrm{Hg})$ & $\begin{array}{l}\text { A } \\
\text { B } \\
\text { R }\end{array}$ & $\begin{array}{l}121 \\
116 \\
126\end{array}$ & & $\begin{array}{l}140 \\
147 \\
146\end{array}$ & \\
\hline Diastolic pressure $(\mathrm{mm} \mathrm{Hg})$ & $\begin{array}{l}\mathbf{A} \\
\mathbf{B} \\
\mathbf{R}\end{array}$ & $\begin{array}{l}79 \\
75 \\
80\end{array}$ & & $\begin{array}{l}90 \\
97 \\
92\end{array}$ & \\
\hline Pulse pressure $(\mathrm{mm} \mathrm{Hg})$ & $\begin{array}{l}\mathbf{A} \\
\mathbf{B} \\
\mathbf{R}\end{array}$ & $\begin{array}{l}42 \\
41 \\
46\end{array}$ & & $\begin{array}{l}50 \\
50 \\
54\end{array}$ & \\
\hline Heart rate (beats/min) & $\begin{array}{l}\mathrm{A} \\
\mathrm{B} \\
\mathrm{R}\end{array}$ & $\begin{array}{l}70 \\
66 \\
77\end{array}$ & 0.05 & $\begin{array}{r}100 \\
96 \\
108\end{array}$ & \\
\hline Plasma cortisol ( $/ \mathrm{g} / 100 \mathrm{ml}$. ) & $\begin{array}{l}\mathbf{A} \\
\mathbf{B} \\
\mathbf{R}\end{array}$ & $\begin{array}{l}17 \cdot 6 \\
21 \cdot 3 \\
20 \cdot 9\end{array}$ & & $\begin{array}{l}34 \cdot 1 \\
30 \cdot 3 \\
32 \cdot 8\end{array}$ & \\
\hline Urine volume ( $\mathrm{ml})$. & $\begin{array}{l}\text { A } \\
\text { B } \\
\text { R }\end{array}$ & $\begin{array}{l}82 \cdot 5 \\
80 \cdot 7 \\
64 \cdot 8\end{array}$ & & $\begin{array}{l}41 \cdot 5 \\
55 \cdot 2 \\
57 \cdot 4\end{array}$ & \\
\hline Total catecholamines $(\mu \mathrm{g} / \mathrm{hr})$ & $\begin{array}{l}\mathrm{A} \\
\mathrm{B} \\
\mathrm{R}\end{array}$ & $\begin{array}{r}3.2 \\
3.8 \\
1.9\end{array}$ & 0.05 & $\begin{array}{l}3.8 \\
7.5 \\
4.9\end{array}$ & $\begin{array}{l}0.001 \\
0.05\end{array}$ \\
\hline Adrenaline $(\mu \mathrm{g} / \mathrm{hr})$ & $\begin{array}{l}\text { A } \\
\text { B } \\
\text { R }\end{array}$ & $\begin{array}{l}0.5 \\
0.5 \\
0.5\end{array}$ & & $\begin{array}{l}1.1 \\
1.2 \\
1.3\end{array}$ & \\
\hline Noradrenaline $(\mu \mathrm{g} / \mathrm{hr})$ & $\begin{array}{l}\mathrm{A} \\
\mathrm{B} \\
\mathrm{R}\end{array}$ & $\begin{array}{l}2.7 \\
3 \cdot 3 \\
1.4\end{array}$ & 0.05 & $\begin{array}{l}2.7 \\
6.3 \\
3.7\end{array}$ & $\begin{array}{l}0.001 \\
0.05\end{array}$ \\
\hline
\end{tabular}

*Group A $(n=18)$, group $B(n=9)$, remainder $(n=21)$.

investigation, the interpolated modifying influences between stimulus and response, which are probably specific both to individuals and to separate physiological systems, require further clarification.

\section{SUMMARY}

Forty-eight medical students taking the second MB anatomy oral examination were studied. Determinations were made of plasma cortisol concentration, systolic and diastolic blood pressure, heart rate, urine volume, and excretion of adrenaline and noradrenaline at the time of the examination and also two months later, for control purposes. In addition, the students completed the Eysenck Personality Inventory, and their phenotypes were determined together with height and weight.

As a means of investigating body build and personality as possible determinants of physiological response patterns, a cluster analysis was carried out which included the stress values of the physiological data together with the measures of body build and personality. Two sub-groups with similarities of $85 \%$ or more were produced and these varied significantly in relation to body build but not in relation to the personality measures.

Group A was of mainly linear physique and did not show a mean stress response of noradrenaline. Group B was predominantly muscular and produced the highest mean noradrenaline release at the time of the examination. The results for plasma cortisol, although not significantly different between the groups, followed a trend found previously, being higher in group A than group B.

It is concluded that factors related to physique appear to modify some physiological responses to psychological stress, while personality as measured by the EPI, does not appear to be a determining 


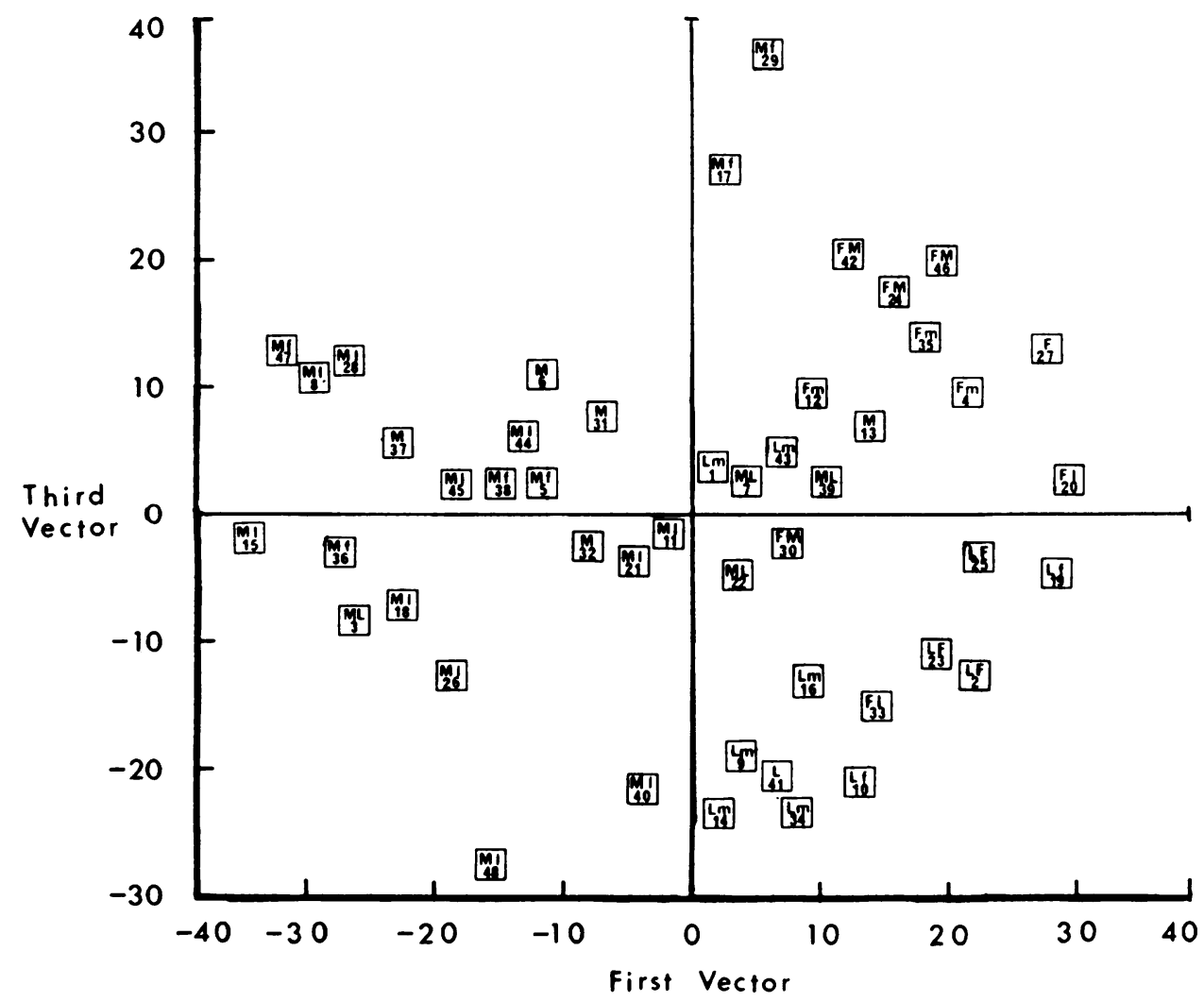

FIG. 2. The co-ordinates of each subject are plotted on latent vectors 1 and 3, and for each is given his number and phenotype classification.

factor. Of the parameters of body build, the most important is the degree of muscularity, and this could be assigned to the first latent vector obtained from the principal co-ordinate analysis in this study. High components of muscularity have been found to be associated with relatively high noradrenaline levels and low plasma cortisol levels in response to psychological stress.

We are grateful to the Dean of St. Thomas's Hospital Medical School, Mr. R. W. Nevin, and to Professor $D$. Davies for their kind co-operation and permission to carry out the study. We thank Professor H. Barcroft, Professor M. Hamilton, and Dr. A. Elithorn for helpful advice; Professor W. G. Murray for laboratory facilities in his department at King's College Hospital; Mr. G. J. S. Ross, of Rothamsted Experimental Station, for carrying out the cluster analysis; Miss E. Kydd and Mr. R. Jagoe for statistical assistance; the medical students who so readily volunteered to take part, and Miss V. Beakley for secretarial help. Dr. Bridges was supported by a grant from the Royal Free Hospital Endowment Fund,
Dr. Jones by the Medical Research Council and Dr. Leak by a grant from King's College Hospital Research Fund.

\section{REFERENCES}

Baron, D. N., and Fraser, P. M. (1968). Medical applications of taxonomic methods. Brit. med. Bull., 24, 236-240.

Bliss, E. L., Migeon, C. J., Branch, C. H. H., and Samuels, L. T. (1956). Reaction of the adrenal cortex to emotional stress. Psychosom. Med., 18, 56-76.

Bridges, P. K, and Jones, M. T. (1967). Personality, physique and the adrenocortical response to a psychological stress. Brit. $J$. Psychiat., 113, 601-605.

- (1968). Relationship of personality and physique to plasma cortisol levels in response to anxiety. J. Neurol. Neurosurg. Psychiat., 31, 57-60.

,-- and Leak, D. (1968). A comparative study of four physiological concomitants of anxiety. Arch. gen. Psychiat., 19, 141-145.

Brunjes, S., and Wybenga, D. (1963). Differential fluorometry in catecholamine determination: a simplified method of calculation. Clin. Chem., 9, 626-630.

Elmadjian, F., Hope, J. M., and Lamson, E. T. (1957). Excretion of $N$ epinephrine and norepinephrine in various emotional states. J. clin. Endocr., 17, 608-620.

Eysenck, H. J., and Eysenck, S. B. G. (1964). Manual of the Eysenck Personality Inventory. University of London Press: London. 
Gower, J. C. (1966). Some distance properties of latent root and vector methods used in multivariate analysis. Biometrika, 53, 325-338.

Hodges, J. R., Jones, M. T., and Stockham, M. A. (1962). Effect of emotion on blood corticotrophin and cortisol concentration in man. Nature (Lond.), 193, 1187-1188.

__, _- Elithorn, A., and Bridges, P. (1964). Effect of electroconvulsive therapy on plasma cortisol-levels. Nature (Lond.), 204, 754-756.

Khosla, T., and Lowe, C. R. (1968). Height and weight of British men. Lancet, 1, 742-745.

Lacey, J. I., Bateman, D. E., and Vanlehn, R. (1953). Autonomic response specificity. Psychosom. Med., 15, 8-21.

Lader, M. H., and Wing, L. (1966). Physiological Measures, Sedative Drugs and Morbid Anxiety, p. 27. Oxford University Press: London.

Leak, D., Brunjes, S., Johns, V. J., and Starr, P. (1962). Adrenal medullary response to insulin hypoglycaemia in hypothyroid patients. J. Lab. clin. Med., 60, 811-817.

Levi, L. (1965). The urinary output of adrenaline and noradrenaline during pleasant and unpleasant emotional states. Psychosom. Med., 27, 80-85.

Martin, B. (1961). The assessment of anxiety by physiological behavioral measures. Psychol. Bull., 58, 234-255.
Mason, J. W. (1959). Psychological influences on the pituitaryadrenal cortical system. Recent Prog. Hormone Res., 15, 345-389.

Moruzzi, G., and Magoun, H. W. (1949). Brain stem reticular formation and activation of the E.E.G. Electroenceph. clin. Neurophysiol., 1, 455-473.

Parnell, R. W. (1953). Physique and choice of faculty. Brit. med. J., 2, 472-475.

- (1958). Behaviour and Physique. Arnold: London.

Schachter, J. (1957). Pain, fear and anger in hypertensives and normotensives. Psychosom. Med., 19, 17-29.

Schildkraut, J. J., and Kety, S. S. (1967). Biogenic amines and emotion. Science, 156, 21-30.

Sheals, J. G. (1964). The application of computer techniques to Acarine taxonomy. Proc. Linn. Soc. Lond., 176, 11-21.

Sokal, R. R., and Michener, C. D. (1958). A statistical method for evaluating systematic relationships. Univ. Kansas sci. Bull., 38, 1409-1438.

— and Sneath, P. H. A. (1963). Principles of Numerical Taxonomy. W. H. Freeman: San Francisco.

Zenker, N., and Bernstein, D. E. (1958). The estimation of small amounts of corticosterone in rat plasma. J. biol. Chem., 231, 695-701. 